\title{
Redes sociales: más allá de la privacidad
}

\author{
Por María-José Sola-Martínez
}

\begin{abstract}
Resumen: A raíz de un cambio en las políticas de uso de Facebook, en febrero 2009 tuvo lugar en IweTel un debate sobre las redes sociales. En él se ampliaron aspectos en torno a este tema que se habían expuesto en anteriores mensajes a la lista. Se deliberó sobre las políticas de uso y su aceptación por parte de cada individuo, sobre la privacidad de los datos y su gestión, se establecieron diferencias entre el cloud computing y las redes sociales, y se apuntó la necesidad de formar a los usuarios en el correcto manejo de las redes sociales como parte del perfil del profesional de la información.

Palabras clave: Redes sociales, Facebook, Privacidad, Formación de usuarios, Protección de datos, Cloud computing, Políticas de uso, IweTel.
\end{abstract}

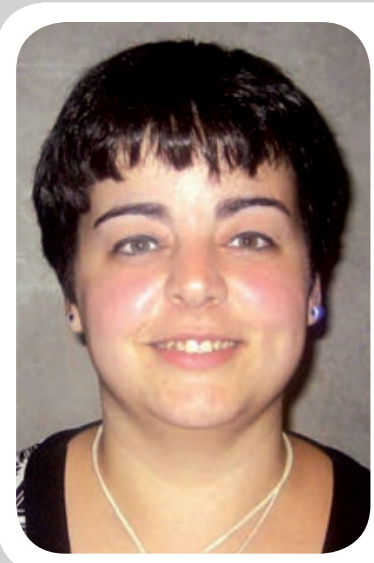

María-José Sola-Martínez es gestora y consultora de contenidos. Diplomada en biblioteconomía y documentación por la Universitat de Barcelona. Hace más de diez años que está relacionada con el mundo de las bibliotecas públicas, durante tres años fue gestora de contenidos del blog Documentaciónofertas de empleo y cursos, y realiza blogs para empresas, profesionales, bibliotecas, etc., como el de la Biblioteca Pública Pompeu Fabra de Mataró. Actualmente prepara un portal sobre cine y literatura de ámbito hispano: "Película basada en".

http://www.peliculabasadaen.com/

\section{Title: Social networks: beyond privacy}

Abstract: Last February, following a change in Facebook's use policies, a discussion about social networks began in IweTel, expanding on multiple facets of previous messages to the list. Topics included: the policies of use and their acceptance by each individual; the privacy of information and its management; the differences between cloud computing and social networks; and the need to train users in the correct use of social networks as part of an information professional's profile.

Keywords: Social networks, Facebook, Privacy, User training, Data protection, Cloud computing, License information, IweTel.

Sola-Martínez, María-José. “Redes sociales: más allá de la privacidad”. El profesional de la información, 2009, julioagosto, v. 18, n. 4, pp. 470-474.

DOI: $10.3145 /$ epi.2009.jul.18

A PESAR DE SER relativamente nuevas, las redes sociales han sido incorporadas a diferentes aspectos de la profesión, por lo que sobre ellas se publican artículos $^{1}$ e informes ${ }^{2}$, son objeto de análisis en blogs ${ }^{3}$, se realizan cursos sobre su gestión y uso en bibliotecas ${ }^{4}$, se presentan comunicaciones en jornadas ${ }^{5}$, etc.

Por todo ello, no podían dejar de aparecer en la lista IweTel, si bien no fueron muchos los mensajes llegados (hasta ese mes de febrero), y casi siempre estaban relacionados con el derecho a la privacidad, o con su uso como medio de difusión de los centros de información ${ }^{6}$ y entidades ${ }^{7}$.

El debate empezó con un mensaje de Roberto C. Álvarez, de la Universidad de Alcalá de Henares, en el que advertía sobre la nueva licencia de uso de Facebook: "al parecer, Facebook ha cambiado una de sus cláusulas de contratación o licencia de uso. Antes, si un usuario se borraba de Facebook, con él se borraban todos sus datos, imágenes, vídeos y demás, sin embargo, ahora se especifica que esa información ¡será 'eternamente' de Facebook! y que debemos fiarnos de su buena

fe... Os remito un pequeño artículo 8 y os invito a buscar más información en la Red. Muchos recelamos de Google por su férreo control y apoyamos iniciativas como la de estas redes sociales, pero cuidado, puede salirnos muy caro en un futuro. ¿Os imagináis campañas de publicidad, catálogos de imágenes, música, vídeos, o una macro base de datos de gustos, relaciones, etc.,

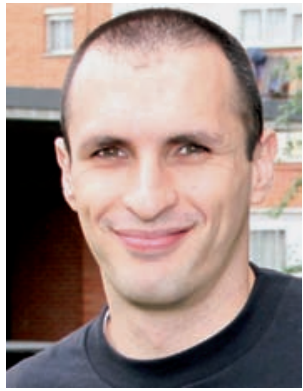

Daniel

Martínez-Ávila 


\section{Cloud computing}

Operar en la nube. Disponibilidad de servidores remotos que permiten que creemos, almacenemos y procesemos en ellos nuestros materiales (documentos de texto, powerpoints, fotos, vídeos...). Se puede decir, por ejemplo, que una determinada colección de fotos reside en "la nube de datos" de Flickr. El acceso se realiza con un navegador estándar. Un ejemplo es Google, con sus servicios Google Docs (suite office) y Picasa (imágenes).

con vuestras vidas y contactos? ¿El gran hermano en Facebook es real? El tiempo nos lo dirá".

\section{vlackon@gmail.com}

A partir de ese momento comenzaron a llegar una serie de mensajes, algunos de los cuales aportaban más información publicada en los medios de comunicación ${ }^{9}$ y otros, comentaban esta noticia e incluso ampliaban los aspectos a analizar. En este grupo de mensajes encontramos el de Daniel Martínez-Ávila, de la Universidad Carlos III de Madrid, en la que se presentaban los temas del cloud computing, la ética y los aspectos legales: "en esta ocasión se han visto obligados a rectificar debido a la presión: 'Facebook nunca ha reclamado la propiedad del material que la gente suba' y 'nunca compartiríamos vuestra información de un modo que no quisiérais', han dicho portavoces de Facebook ${ }^{10}$. Como vemos, los verdaderos peligros del cloud computing son mucho más que la conexión o disponibilidad del servidor, están más relacionados con aspectos éticos y legales".

\section{daniel.martinez@uc3m.es}

A este enfoque le siguió la réplica de Marcos Ros-Martín, del Instituto Tecnológico de la Construcción (Aidico), subrayando que la verdadera importancia de la noticia era la gestión de la privacidad de los usuarios de las redes sociales y anotaba el desconocimiento de la visibilidad de la información que se difunde en ellas: "respecto a la privacidad en las redes sociales, en realidad, a lo que nos enfrentamos

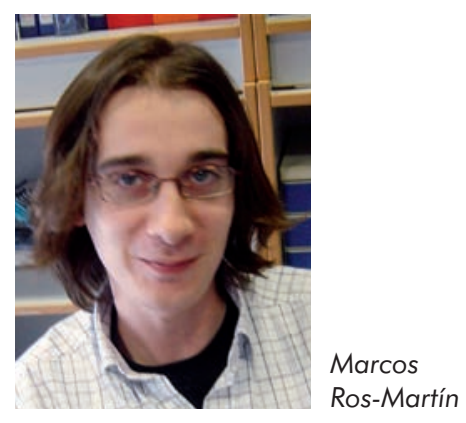

es a nuestra incapacidad para gestionarla. La denuncia que ha saltado en este momento no se debe a lo que Facebook declare ahora en sus términos de uso "que toda imagen y texto que se añada será suyo a perpetuidad". Esta cláusula ya existía. Lo que preocupa es que si uno se da de baja, ellos se guardan el derecho a disponer de su información. Ante la polémica Facebook se ha defendido diciendo que lo hace para que los amigos que el usuario deja en la red social puedan seguir disponiendo de esos materiales. Se podría contemplar como el registro de nuestra memoria en dicha red social. En el caso de Facebook, las agencias de protección de datos están dando la alarma sobre la violación de nuestra privacidad, las asociaciones de protección de menores están intentando inculcarles al menos una educación 2.0 sobre lo que deben o no deben publicar en este tipo de redes. En realidad, cuando usamos una red social sufrimos una especie de efecto burbuja, creemos que nadie está observando lo que publicamos, lo que compartimos (tal vez porque consideramos que utilizar una red social es como utilizar el Messenger o el correo electrónico), aunque en realidad es- tamos compartiendo mucha información, tal vez demasiada".

marcos.ros@aidico.es

\section{"Respecto a la privacidad en las redes sociales, en realidad a lo que nos enfrentamos es a nuestra incapacidad para gestionarla" (Marcos Ros- Martín)}

Por su parte, Nieves González-Fernández-Villavicencio, de la biblioteca de la Universidad de Sevilla, presentaba la cuestión de la concienciación social sobre el uso de las redes sociales y la formación en su correcto empleo: "considero que aparte de las actuaciones sociales o legales que se deriven de las políticas de privacidad que fijan las redes sociales, hace falta una concienciación social de los peligros y riesgos de la Red, pero no sólo denunciando los casos, sino formando a los ciudadanos, jóvenes, estudiantes, usuarios reales o potenciales de estas redes, en su uso. Mientras sigamos considerando que son 'sólo' nuevas tecnologías, 'cosas' de jóvenes y frikis, y sigamos menospreciando su presencia e impacto en la sociedad, dándole la espalda a su integración en los programas formativos de cualquier tipo y de cualquier institución, nos seguirán sorprendiendo noticias como ésa. Nos enseñan (más o menos) a comportarnos en sociedad, aprendemos a circular por las calles, pero nadie

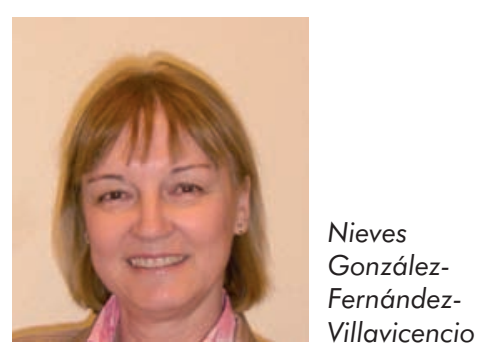


(o casi nadie) nos enseña a movernos por la Red, ni nos advierte de sus peligros y riesgos". Más adelante, la propia Nieves González y la Biblioteca ETSIT de la Universidad Politécnica de Madrid aportarían una serie de enlaces sobre esta línea de formación ${ }^{11,14}$.

nievesg@us.es

Al hilo del uso de la información privada en las redes sociales Francisco Tosete-Herranz, quiso ahondar comentando: "si la Web social es perder tu privacidad y el derecho a manejar tus datos privados como quieras para que puedan ser utilizados sabe Dios cómo, creo que hace falta una reflexión urgente sobre la misma y sobre el modelo en el que nos encontramos. La Web está introduciendo un nuevo modelo político, económico y social. Los cambios están en marcha y los está dictando un grupo muy reducido de actores con la capacidad de desarrollar las tecnologías que impactan cotidianamente en nuestras vidas. Urge como mínimo una reflexión crítica".

\section{ftosete@imaginas.net}

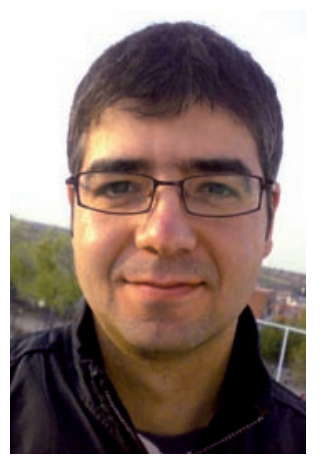

Francisco

Tosete-Herranz

Llegados a esta punto del debate, Paco López-Hernández, de la biblioteca de la Universidad Carlos III de Madrid, se preguntaba si la privacidad de los datos no está ya quebrantada desde hace mucho: "da la impresión de que no sólo los gobiernos, sino muchas empresas privadas, compañías de servicios, etc., llevan años y años manejando esos datos y poca gente se ha escandalizado. ¿No nos están llamando cada dos por tres por teléfono para vendernos algo? ¿O es que vosotros no habéis recibido la típica carta de esa empresa o compañía que tiene vuestros datos y en la que nos dice que 'si no les mandamos por escrito nuestra negativa' se los van a pasar a terceros? Al fin y al cabo, los datos que damos en esas redes sociales son los que nosotros queremos. Y encima pueden ser hasta falsos. Sin embargo, son ciertos los que damos a la Seguridad Social, a las compañías telefónica, de agua, gas, luz..."

pacol@db.uc3m.es

\section{"Creemos que nadie observa lo que publicamos en una red social, pero en realidad estamos compartiendo mucha información" (Marcos Ros- Martín)}

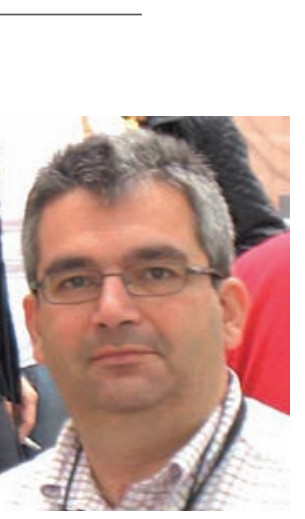

Francisco López-Hernández

A este mensaje le siguió el de Daniel Martínez-Ávila, quien ponía de nuevo sobre la mesa la inclusión del cloud computing dentro de las redes sociales. Entonces Marcos Ros intervino para separar los dos conceptos y abogar por la redacción de una ley sobre protección de datos a nivel mundial: "creo que no habría que mezclar lo que es el cloud computing y las redes sociales. Es cierto que muchos de los desarrollos de la Web 2.0, como los blogs, han tendido ha crear sus propias redes sociales como están intentando en Weblogs SL. Pero el fin último de la Web 2.0 no es trazar las relaciones persona a persona de un individuo como se hace en Facebook, sino que lo que se intenta es compartir y construir conocimiento (blogs y wikis). Tal vez Flickr y YouTube se acercan un poco más a las redes sociales aunque su finalidad y la manera de interactuar con ellas no es la misma que Facebook. Sobre el cloud computing, es lógica la crítica que se le hace y los peligros que entraña tanto para empresas como para instituciones que apuesten por esa manera de trabajar. Yo nunca pondría documentos sensibles o críticos para mi organización en Google Docs, por ejemplo, y tal vez ese es el trasfondo de lo que dice Stallman. Aunque claro, ¿qué va a decir un hombre que no usa navegadores web (12 $^{12}$ fin, tampoco hay que volverse excesivamente luditas y mantener la mirada crítica porque Facebook está ahí para quedarse. Aunque tal vez vaya siendo hora de que nuestros políticos se pongan a redactar una ley de protección de datos a escala global como ya se comienza a proponer".

\section{"Hace falta una concienciación social de los peligros y riesgos de la Red, formando a los usuarios" (Nieves González)}

En ese momento saltó la noticia en los medios de que Facebook no utilizaría la información contenida en los perfiles eliminados ${ }^{13}$. Tras esta novedad, el debate fue dirigido por José-Ángel Maestro-Cano, de la biblioteca general de la Universidad Politécnica de Valencia, hacia el tema legal sobre la opción 
de aceptar o denegar las nuevas normas aplicadas por Facebook: "según entiendo yo (con mis limitados conocimientos legales), los términos y condiciones de uso podrían ser considerados como un elemento contractual: yo te ofrezco tal servicio, de pago o gratuito bajo estas condiciones y tú las aceptas o no. Esto se aplica al menos en España incluso a los folletos publicitarios, que generan una obligación para quien ofrece el servicio o producto correspondiente. Si yo me abro un perfil en Facebook, lo hago bajo las condiciones existentes en ese momento. Si Facebook desea modificarlas luego unilateralmente ¿no tiene obligación legal de hacer una

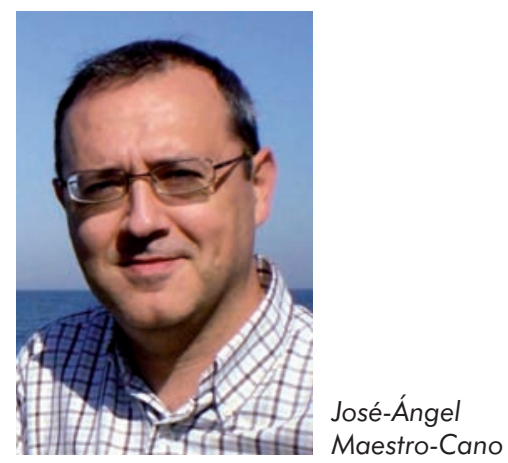

notificación expresa a los usuarios de esa modificación para que cada uno decida si desea aceptarlas o no? Medio de hacerlo, evidentemente, lo tiene por la misma naturaleza de su servicio. ¿El banco en que tenéis vuestra nómina e hipotecas os puede cambiar porque sí los términos o intereses de su servicio, sin una simple notificación? Dicho de otra forma: ¿qué libertades u obligaciones legales tiene Facebook (o cualquier otro sitio web) a la hora de modificar los términos (contrato) del servicio? Sé que la cuestión quizá parece un poco tiquismiquis, pero es que estas grandes compañías sí juegan con esos aspectos y los usuarios deberíamos hacerlo también para defendernos llegado el caso".

jmaestro@bib.upv.es
Félix Martínez, de la Biblioteca Pública Jordi Rubió i Balaguer de Sant Boi de Llobregat, Barcelona: "de entrada lo que hay es un contrato de adhesión, que ya está redactado por una de las partes y la otra sólo puede aceptarlo o no, sin ninguna posibilidad de negociar. Estos contratos son los propios de las compañías de servicios. Ahora bien, la no capacidad de negociar no implica la aceptación de cláusulas abusivas, que en este tipo de contratos son nulas de derecho, ya que el no poder modificarlas las suele invalidar. A mí me dan un poco de grima frases como 'totalmente y a perpetuidad', y demás lindezas por el estilo que hay en este contrato, y no creo que por mucho que se lo hayan mirado, jurídicamente se pueda aguantar por ningún sitio".

felixgmartinez@yahoo.es

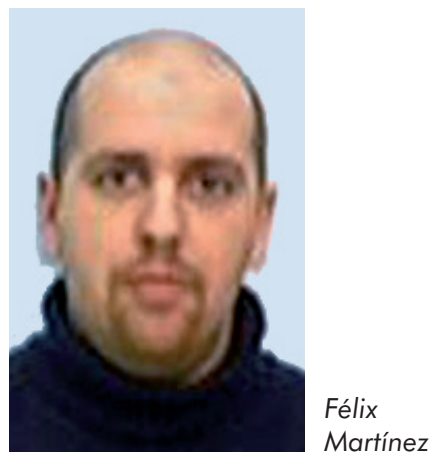

\section{"No debemos olvidar nuestro papel como formadores en competencias digitales al ser profesionales de la información" (Elvira San- Millán-Fernández)}

El asunto que se retomaba en ese momento era la división entre el cloud computing y las redes sociales manifestada por Marcos Ros, con la contestación de Luis de la

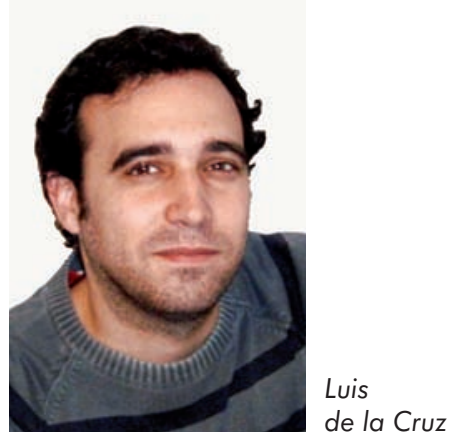

Cruz, de la Biblioteca Pública de Usera en Madrid, en la que además exponía su parecer sobre Facebook y los blogs: "no estoy de acuerdo con esa diferenciación que haces entre red social y Web 2.0. La red social es un conjunto de personas y preexiste a Facebook y similares, y es precisamente la explosión de ese componente de relaciones sociales lo que está en la base de la red social (o 2.0). En mi opinión el término se utiliza mal: son herramientas para facilitar la creación de redes sociales. Los blogs que uno lee, la gente con la que se relaciona en internet son su red social, y si además se comparte cierta cultura común puede ser una comunidad. Conozco miles de ejemplos de comunidades de blogs no necesariamente declaradas como tal, en el entorno de un grupo, aunque no estén bajo un mismo paraguas y precisamente Weblogs $S L$ no me parece una comunidad, ni tan siquiera una red social, sino una serie de publicaciones comerciales en formato blog, aunque en cambio seguramente se habrá formado una comunidad en torno a alguno de sus blogs y sus editores tendrán su propia red social de contactos. Entonces ¿porque surge Facebook? (y antes otros): porque la estructura de la Red es distribuida y tener perfectamente mapeados esos contactos es complejo. Personalmente creo que estos sistemas constriñen, tratan de meter internet en una caja y creo que pasado un tiempo, cuando la mayoría de los usuarios sean avanzados dejarán de tener sentido más que como un simple foro de 
los de toda la vida, para un interés concreto. Nuestra identidad online será más distribuida (con nuestros blogs o páginas personales, nuestras fotografías y vídeos en repositorios separados, nuestro Open ID como llave para entrar en la casa de los vecinos, nuestras herramientas de agregación de contenidos para tener controladas las andanzas de nuestra red social, etc. $\mathrm{O}$ eso espero al menos".

\section{luisroberto.delacruz@madrid.org}

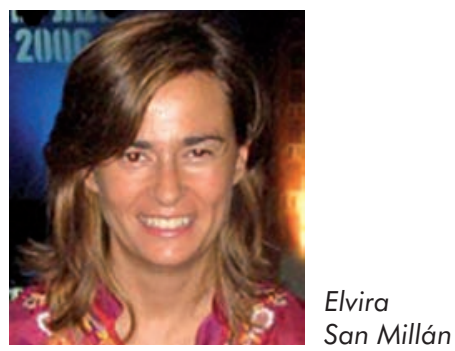

Cerrando la discusión, Elvira San-Millán-Fernández, de la Universidad Rey Juan Carlos de Madrid, rescató la formación en redes sociales, señalando que: "no debemos olvidar nuestro papel como formadores en competencias digitales al ser profesionales de la información, faceta reivindicada cada vez más por programas alfin 2.0, o iniciativas como las de la Universidad de Sevilla o el ejemplo del uso de Facebook por la Biblioteca Etsit $^{14}$ de la Universidad Politécnica de Madrid. Hay muchos más. [...] $\mathrm{Ha}$ de existir un equilibrio entre lo que debemos exigir a las redes sociales para que protejan nuestra intimidad y no introduzcan cláusulas abusivas, como la de Facebook, que tuvo que retirar recientemente; y nosotros, formadores, padres, poderes políticos, la sociedad en general, que no debemos hacer cesión de nuestra obligación de formar a nuestros hijos, alumnos, etc., en el uso de las redes sociales".

elvira.fernandez@urjc.es

\section{Notas}

1. El profesional de la información. "Redes sociales". El profesional de la información, 2008, noviembre-diciembre, v. 17 , n. 6.

2. Observatorio Nacional de las Telecomunicaciones y de la Sociedad de la Información (Ontsi). Libro blanco de los contenidos digitales en internet. The Cocktail Analysis. Herramientas de comunicación online: las redes sociales. Instituto Nacional de Tecnologías de la Comunicación (Inteco). Estudio sobre la privacidad de los datos personales y la seguridad de la información en las redes sociales online.

http://www.red.es/articles/detail.action?sec= $228 \& i d=2660$

http://www.tcanalysis.com/uploads/2008/11/ informe_observatorio_redes_sociales.pdf https://www.agpd.es/portalweb/canaldocumentacion/ publicaciones/common/Estudios/estudio_inteco_ aped_120209_redes_sociales.pdf

3. El documentalista enredado o Deakialli. En otras vertientes: Genbeta, Whatnew o Loogic.

http://www.documentalistaenredado.net/tag/ redes-sociales/

http://www.deakialli.com/tag/redes-sociales/ http://www.genbeta.com/tag/red+social

http://wwwhatsnew.com/category/redes-sociales/ http://loogic.com/category/aplicaciones-web/ redes-sociales/

4. Uno de los últimos ha sido Reflexionando la Web social como actitud. Herramientas 2.0. Teoría y práctica, de la Red de Bibliotecas de la Comunidad de Madrid, cuyas ponencias se pueden consultar en su web.

http://cursowebsocialbibliotecamadrid.blogspot. com/2009/02/cobtenidos-del-curso.html

5. Por ejemplo, las XI Jornadas de Documentación organizadas por Fesabid, celebradas en mayo en Zaragoza.

http://www.fesabid.org/zaragoza2009/

6. Algunos ejemplos: biblioteca de la Universidad de Sevilla, Biblioteca Pública de San Miguel, Biblioteca Nacional y la Red de Bibliotecas del Instituto Cervantes. http://www.facebook.com/profile.php?id= 1616083331

http://www.facebook.com/people/BibliotecaPublica-San-Miguel/1520618978

http://www.facebook.com/bne

http://www.facebook.com/pages/MadridSpain/Red-de-Bibliotecas-del-InstitutoCervantes/52809248216

7. Como jornadas: Facebook de las XI Jornadas de Documentación organizadas por Fesabid. http://es-es.facebook.com/people/FesabidFesa/773093885

8. http://www.cadenaser.com/tecnologia/articulo/ quien-dueno-informacion-facebook/csrcsrpor/ 20090217csrcsrtec_3/Tes

9. Por ejemplo: Hodgkinson, Tom. With friends like these...

http://www.guardian.co.uk/technology/2008/ jan/14/facebook

10. http://tech.slashdot.org/article.pl? sid=09/02/ $17 / 2213251 \&$ from $=$ rss

11. Corredoira, Loreto. Redes sociales: controla tu identidad. Villalba, Marta. El "caso Marta" desvela riesgos para los menores en las redes sociales. Cuida tu reputación digital: 10 consejos para usuarios de redes sociales.

http://www.diariodesevillalanueva.es/content/ view/2966/446/

http://www.abc.es/20090222/nacional-sociedad/ redes-sociales-intimidad-menores-20090222. html

http://www.slideshare.net/biblioteca.etsit/ reputacin-digital

12. http://alt1040.com/2008/01/richard-stallmanno-usa-navegadores-web

13. Riveiro, Aitor. Facebook no utilizará la información de los perfiles eliminados. La red social recula ante las quejas de los usuarios, acepta volver a los antiguos términos de uso y pide colaboración para redactar unos nuevos.

http://www.elpais.com/articulo/internet/Facebook/utilizara/informacion/perfiles/eliminados/ elpeputec/20090218elpepunet_1/Tes

14. Blog de la Biblioteca de la Esc Técn Sup de Ing de Telecomunicación

http://bibliotecaetsitupm.wordpress.com/ 2009/03/31/\%C2\%BFhimno-para-facebookconsejos-bibliotecaetsit-para-usuarios-deredes-sociales/

\section{María-José Sola-Martínez}

http://www.mariajosesola.com.es mjs@mariajosesola.com.es

\section{ibersid \\ XIV Encuentros internacionales sobre sistemas de información y documentación Zaragoza, 5-7 de octubre de 2009 Universidad de Zaragoza http://www.ibersid.org}

